\title{
Weldable fibre Bragg grating sensors for steel bridge monitoring
}

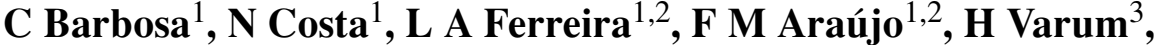 \\ A Costa $^{3}$, C Fernandes ${ }^{3}$ and $\mathrm{H}$ Rodrigues $^{3}$ \\ ${ }^{1}$ FiberSensing, R Vasconcelos Costa, 277, 4470-640 Maia, Portugal \\ ${ }^{2}$ INESC Porto, Campus da FEUP, R Dr Roberto Frias, 378, 4200-465 Porto, Portugal \\ ${ }^{3}$ Civil Engineering Department, University of Aveiro, Campus Universitário de Santiago, \\ 3810-193 Aveiro, Portugal
}

Received 21 April 2008, in final form 4 September 2008

Published 17 October 2008

Online at stacks.iop.org/MST/19/125305

\begin{abstract}
For applications related to the structural health monitoring of steel bridges, novel weldable strain and temperature sensors based on fibre Bragg gratings were developed. These sensors, which can be directly welded to metallic structures, reveal linear responses over typical required measurement ranges and stability over thousands of load and temperature cycles. Proper installation procedures and in-field mechanical protection were also developed and implemented. The significance of the developed sensors was demonstrated through the installation of a complete sensing network on a new circular pedestrian bridge in Aveiro, Portugal, where it was used for loading tests, and also for in-service monitoring of its structural health.
\end{abstract}

Keywords: fibre Bragg grating sensors, weldable sensors, structural health monitoring, metallic bridge

(Some figures in this article are in colour only in the electronic version)

\section{Introduction and scope}

In the last few years, the examples of application of fibre Bragg grating sensors for structural health monitoring have become more and more common [1,2]. The explanation for this fact relies not only on the particularly appropriate characteristics associated with these devices for measuring the most relevant structural parameters, without revealing a number of disadvantages usually attributed to conventional sensors, but also on the growing number of companies operating in the area of fibre optic sensing [3, 4]. Even if standardization still seems a little bit far for fibre Bragg gratingbased sensing systems (up to now, only a few isolated efforts are known in this direction [4-7]), these companies are already offering nowadays an interesting range of sensors based on this technology, as well as several types of measurement units with increasing capabilities. From the point of view of the sensors, important evolutions have been made in terms of parameters that can be measured, packaging oriented to a variety of applications and long-term reliability. In what concerns the measurement units, new improvements included increasing the number of interrogated sensors, higher dynamic ranges and sampling rates, more compactness and portability, and inclusion of data logging and data transmission capabilities [8].

Nevertheless, real-world applications are always fruitful in terms of new challenges. If the fibre Bragg grating-based sensors are intended to monitor real structures, they must be specifically tailored to fulfil the requirements of existing applications and also, most important, must be comprehensible to the technicians that are familiar with conventional electricbased instrumentation.

One interesting case is the monitoring of large steel structures such as bridges. For this particular application, fibre Bragg grating sensors should follow the most suitable product design available from the conventional instrumentation world, which is the weldable strain gage. This type of sensor is clearly preferable since it minimizes surface preparation requirements and precludes epoxy curing processes during installation. Instead, spot welding is used, which can be accomplished with a portable stored-energy hand-probe spot welder. This helps to reduce the installation time and 


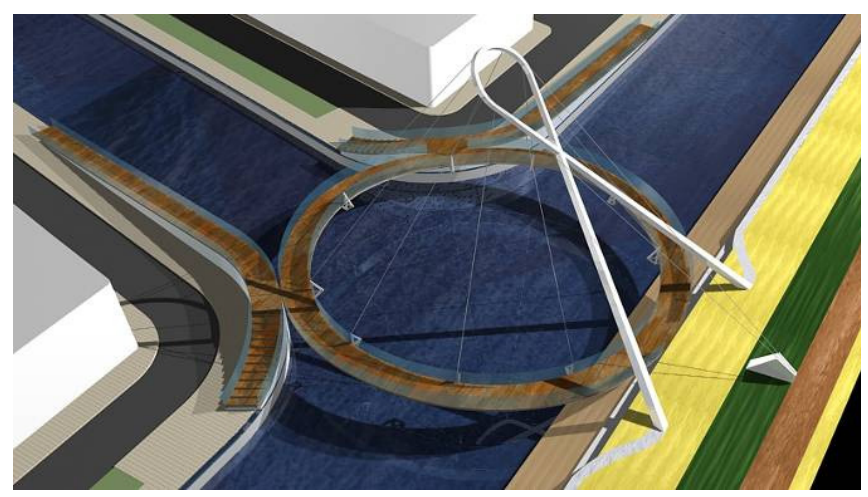

Figure 1. Project of the new circular pedestrian steel bridge over the São Roque and Botirões channels in Aveiro, Portugal.

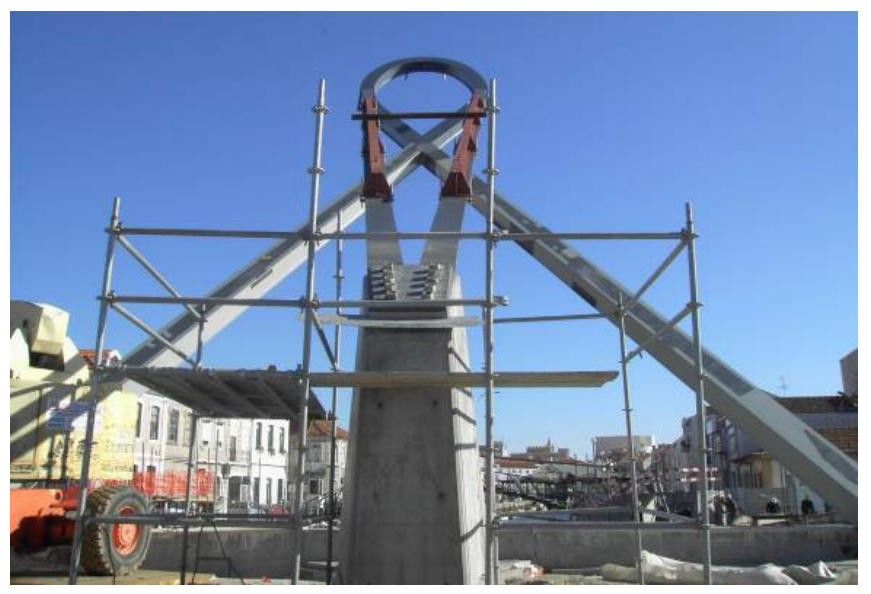

Figure 2. Construction of the new circular pedestrian steel bridge over the São Roque and Botirões channels in Aveiro, Portugal.

also ensures proper performance of the sensor at higher temperatures and harsh environments, rendering unnecessary the use of elevated-temperature-curing adhesives. On the other hand, environmental protection can be as easily applied to a welded sensor as to an adhesively bonded gage.

In this paper, new strain sensors based on fibre Bragg gratings are presented. These sensors were developed for being directly welded to steel structures following similar procedures to those of conventional weldable strain gages. For referencing purposes, weldable fibre Bragg grating-based temperature sensors were also developed. In addition, proper protection means and installation procedures were established and implemented. Testing results on sensors reveal linear response for the required measuring range and stability under cyclic loading and temperature ageing.

The developed sensors were used for monitoring the new circular pedestrian steel bridge over the São Roque and Botirões channels in Aveiro, Portugal (figures 1 and 2). The bridge instrumentation followed a monitoring plan designed according to previous numerical analysis of the structure. The measurements obtained with the installed fibre Bragg grating sensing network allowed the improvement and calibration of the numerical models, as well as the real-time monitoring of the bridge structural health during loading tests and in service.

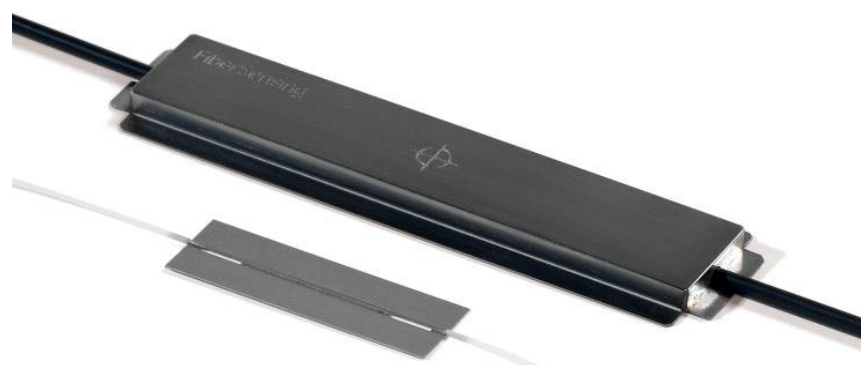

Figure 3. Fibre Bragg grating weldable strain (or temperature) sensor and protection cap for fibre Bragg grating weldable sensors.

\section{Development of the weldable sensors}

Figure 3 shows the developed weldable fibre Bragg grating strain gage. It consists of a capillary stainless steel tube (inside diameter $0.25 \mathrm{~mm}$ /outside diameter $0.5 \mathrm{~mm}$ ) containing the sensing element glued with a thermal curing epoxy. The tube is laser welded to a thin stainless steel base (length $45.0 \mathrm{~mm}$ /width $15.0 \mathrm{~mm} /$ thickness $0.3 \mathrm{~mm}$ ) that is used for direct spot welding to the steel structure. The input/output fibres are protected with a standard $900 \mu \mathrm{m}$ buffer. For installation purposes, a protective stainless steel cap was also developed that can be directly welded to the structure by using the same hand-probe spot welder (figure 3). Input/output fibres enter/exit this cap already protected by a $3 \mathrm{~mm}$ PVC buffer with an internal stainless steel coil. The weldable temperature sensor has exactly the same mechanical design as the strain one. The only difference is that the sensing element inside the capillary stainless steel tube is properly strain isolated.

To enable the production of the FBG weldable sensors in large quantities and in a reliable and reproducible way, a special assembling set-up was developed, which is shown in figure 4. This set-up allows fibre tension definition through a high-precision translation stage and uses high-precision linear bearings for insertion of the FBG sensor inside the capillary tube. The curing process is real time monitored by a software application that also controls in closed loop the micro-heaters in place. After the manufacturing process, all the sensors undergo post-processing accelerated ageing.

To evaluate the performance of the strain weldable sensor, it was first spot welded to a stainless steel bar, and then submitted to a loading test in a standard mechanical testing machine (figure 5). For calibration, the Bragg wavelength was monitored while increasing and decreasing load cycles were applied to the bar at constant temperature. The strain weldable sensors were defined with ranges next to the yield strength of common steel structures $( \pm 2 \mathrm{~m} \varepsilon)$. The sensor response is shown in figure 6 , which reveals a sensitivity of $1.2 \mathrm{pm} \mu \varepsilon^{-1}$. The bar was then submitted to thousands of load cycles (2000 load cycles) in order to evaluate the stability of its response under repeated loading. As can be inferred from the results in figure 7 , the sensor response is stable and reliable. 


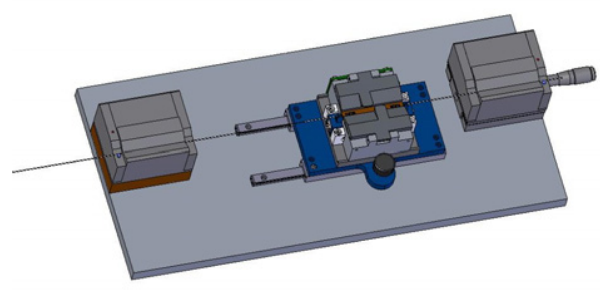

(a)

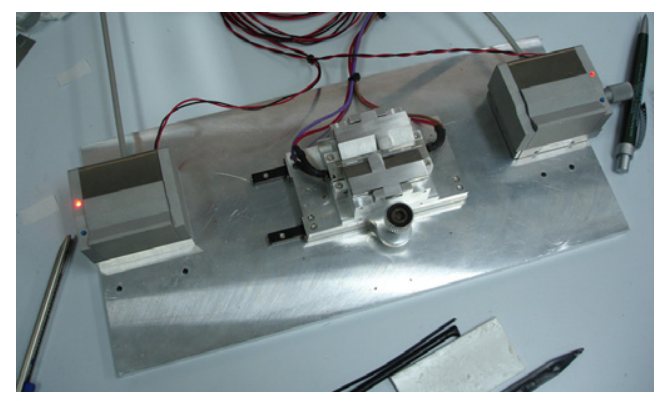

(b)

Figure 4. Weldable sensors assembling set-up: (a) CAD project; (b) implemented set-up.

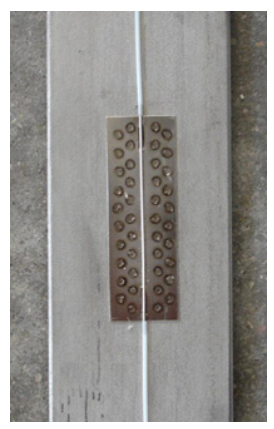

(a)

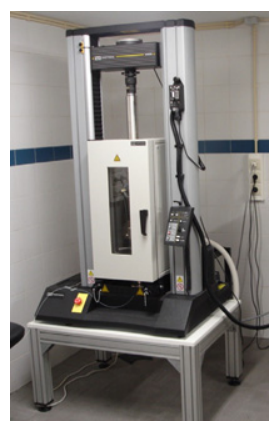

(b)
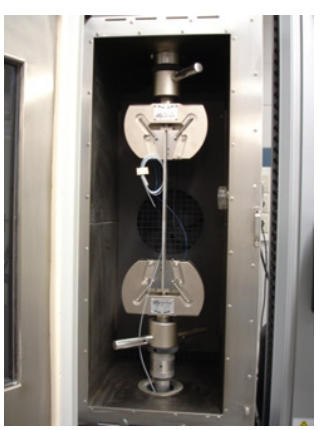

(c)
Figure 5. Mechanical tests: $(a)$ instrumented bar; $((b)$ and $(c))$ testing machine.

To characterize the weldable temperature sensor, it was placed in a climatic chamber and the Bragg wavelength was monitored while the temperature was varied from $-20{ }^{\circ} \mathrm{C}$ to $80{ }^{\circ} \mathrm{C}$. Figure 8 shows the obtained result for a single temperature cycle. From this result, a linear sensitivity of $10 \mathrm{pm}^{\circ} \mathrm{C}^{-1}$ can be determined for the expected environmental temperature range. The long-term reliability of the sensor was also evaluated applying a few consecutive high temperature cycles. Data in figure 9 refer to tests where the sensor has been subjected to more than $65 \mathrm{~h}$ at $80{ }^{\circ} \mathrm{C}$ without moisture control. It indicates no significant degradation of the sensor response with subsequent temperature ageing.

\section{Implementation of a sensing network on a steel bridge}

The sensing network implemented in the circular pedestrian steel bridge under analysis is shown in figure 10. It consists of 32 weldable strain sensors and 8 weldable temperature sensors deployed in a star configuration arranged in 8 branches. Figure 11 shows a typical measurement branch. The access to all the sensor branches is concentrated in a connection box placed on the structure concrete anchorage pier.

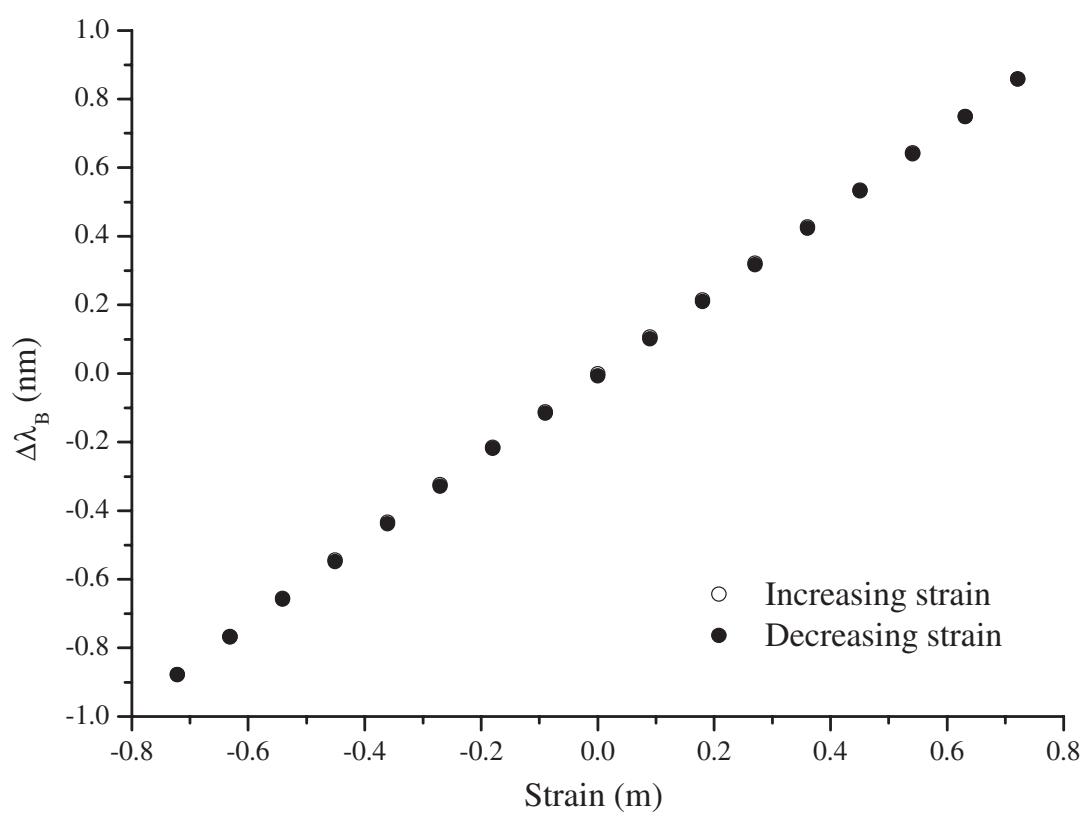

Figure 6. Calibration of the weldable strain sensor. 


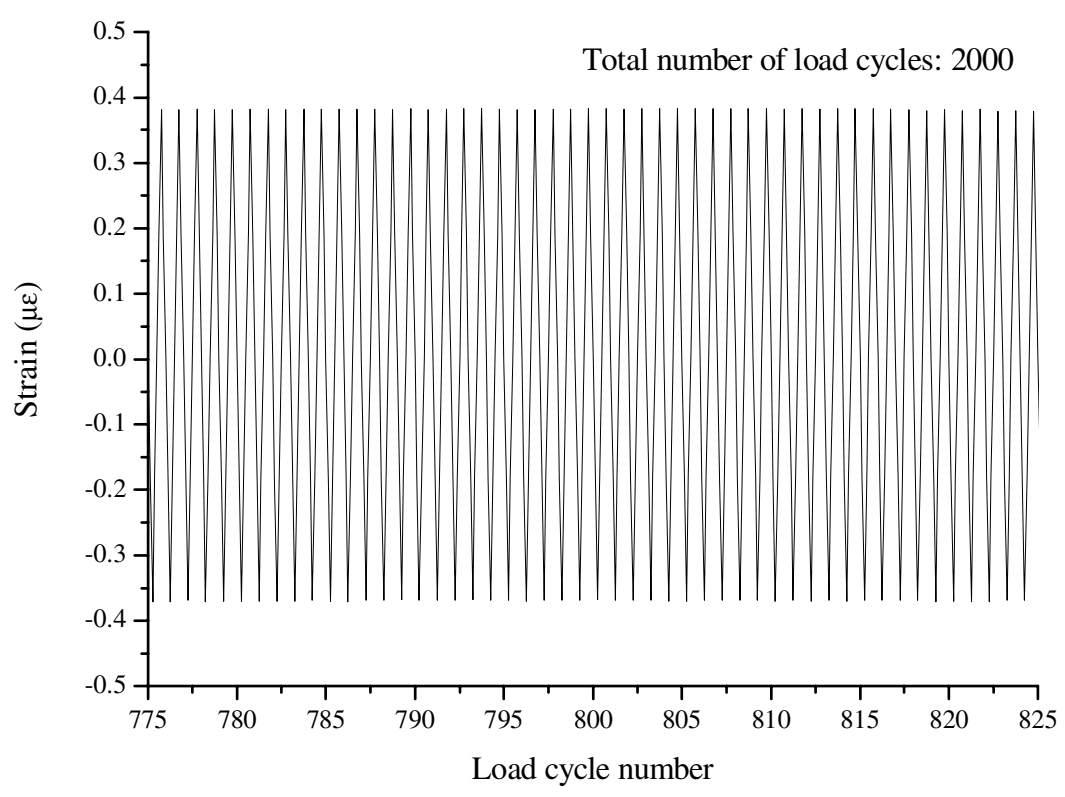

Figure 7. Weldable strain sensor response under cyclic loading.

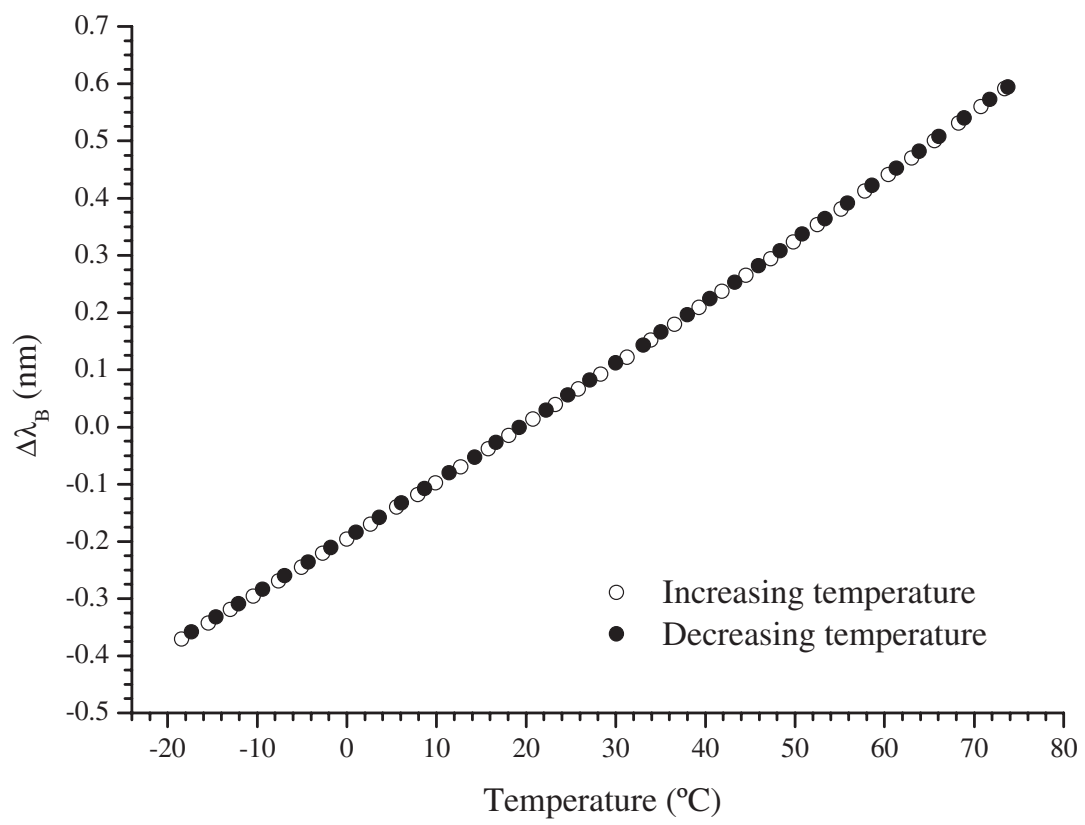

Figure 8. Calibration of the weldable temperature sensor.

The monitoring plan was drawn according to the previous numerical analysis of the structure. It was expected the fibre optic strain sensing network to give the stress distribution in the most relevant structural elements of the bridge, namely the suspension cables and beams. The measurements obtained with the installed fibre Bragg grating sensing network should also allow the improvement and calibration of the predicted models, as well as the real-time monitoring of the bridge structural health during loading tests and service. The temperature sensing network was defined according to the localization of the strain sensors and considering regions where temperature is assumed identical. The configuration of the sensing network was further determined by aesthetic considerations, since it was important to minimize any visual impact in the structure.

The installation of the sensing network started when the bridge structure was already constructed. This fact has increased the difficulties associated with the deployment of the sensors and connection cables. Therefore, special care was taken to make the installation process easier while ensuring proper protection of all the sensors and connections from environmental effects, particularly concerning moisture. Although the sensor is produced with stainless steel, the welding points and the unprotected area from the structure are sensible to corrosion, meaning that the contact of this area with air and water needs to be properly protected (waterproofing sealant tape). The installation of each sensor comprised three 


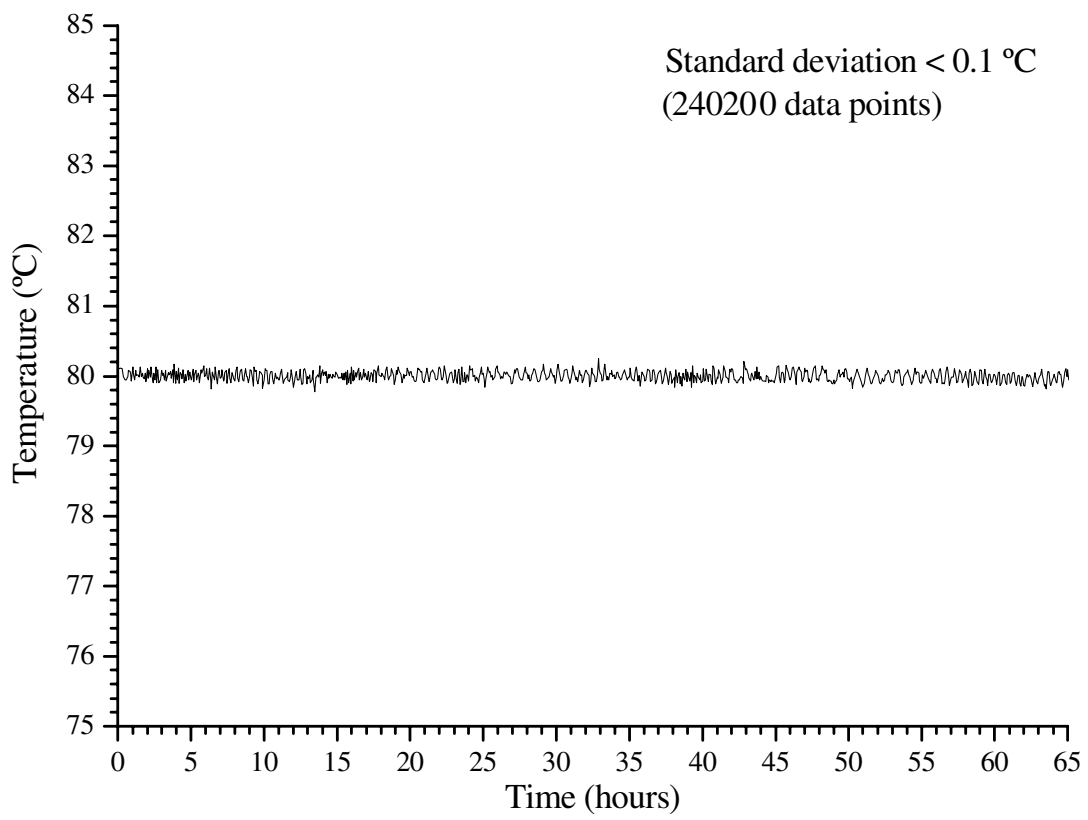

Figure 9. Weldable temperature sensor ageing.

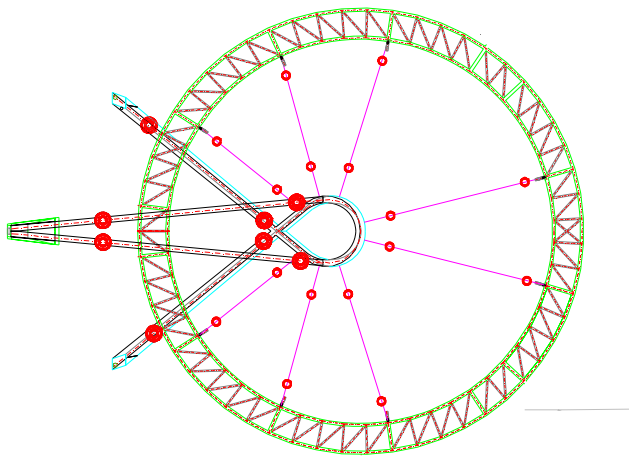

(a)

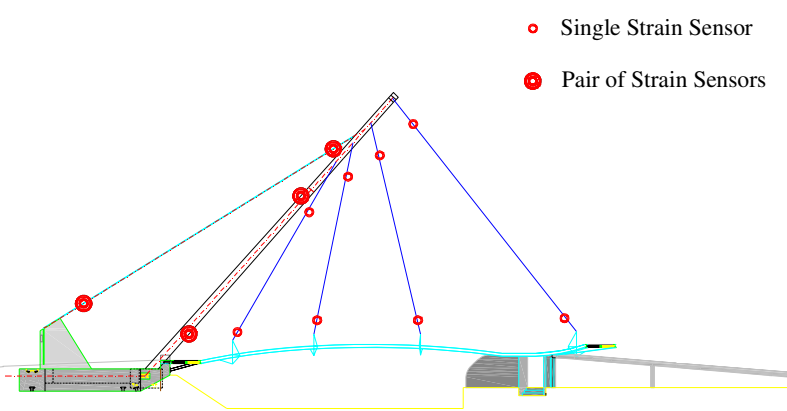

(b)

Figure 10. Bridge monitoring plan: $(a)$ top view; $(b)$ side view.

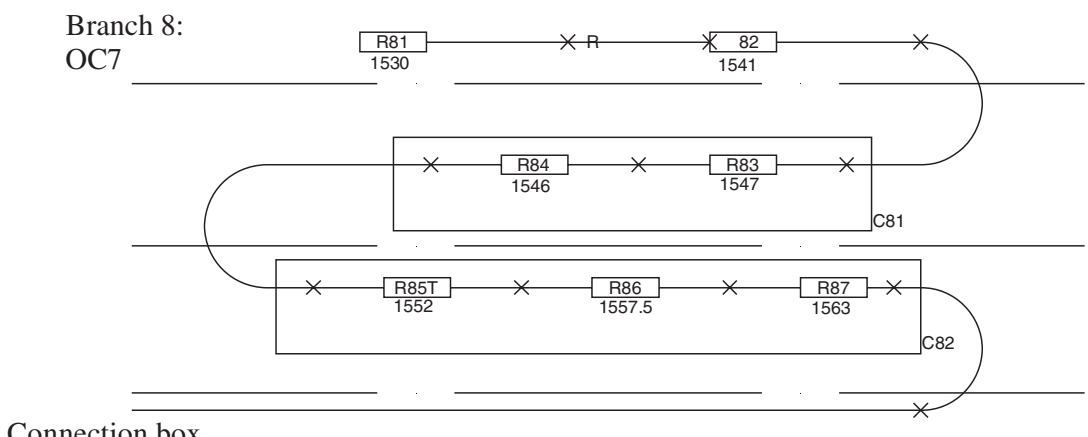

Figure 11. A typical branch of the sensing network.

phases: regularization and cleaning of the surface, welding of the sensor and protection of the welded sensor. After the welding process, all the sensors were covered with hermetic tape before being protected with the weldable cap, which was sealed afterwards. Figure 12 exemplifies the complete process of installation of a sensor in the bridge. Even if this process is not complex, installation of the network in the constructed bridge was not an easy task, especially concerning the cylindrical suspension cables, as can be understood from figure 13.

All the fibres in the network $(\sim 0.5 \mathrm{~km}$ in total) were protected with a $3 \mathrm{~mm}$ PVC buffer with an internal stainless 


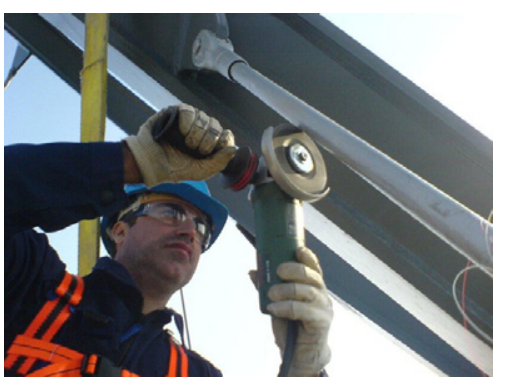

(a)

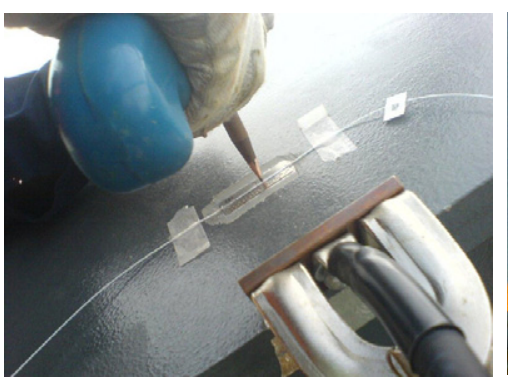

(b)

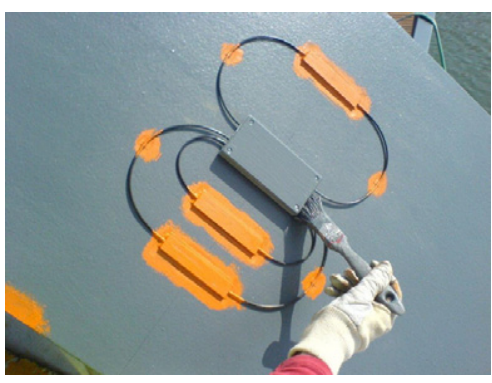

(c)

Figure 12. Installation process of a weldable sensor: regularization and cleaning of the surface, sensor welding and sensor protection.

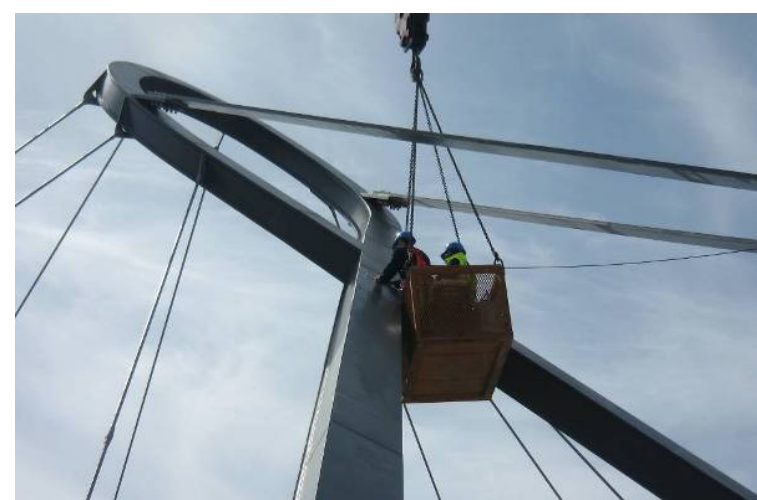

Figure 13. Installation of sensors in a bridge steel beam.

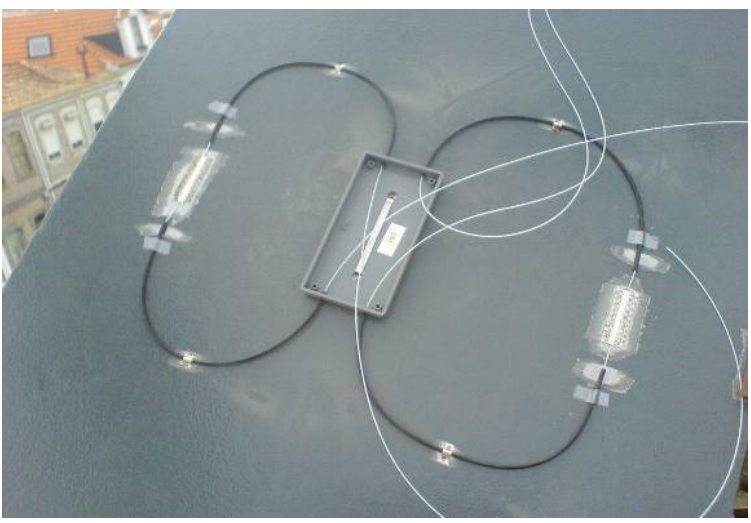

Figure 14. Boxes for accommodation of connections and splices.

steel coil, and fixed to the steel structure by using weldable straps (figure 14). Connections and splices in the network were accommodated in small hermetic boxes that were also spot welded to the structure, also shown in figure 14 .

The performance of all the sensors during and after the installation process was evaluated using a portable, batterypowered measurement unit from FiberSensing (portable BraggMETER [9]), which is shown in figure 15.

As an example, the spectra of the sensors corresponding to branch 8 are shown in figure 16. These were obtained with the BraggMETER measurement unit after installation of the sensing network. During these and other subsequent tests, the entire sensing network could be easily accessed through a

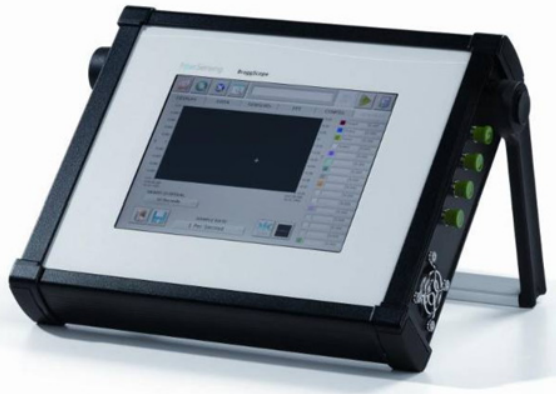

Figure 15. Portable BraggMETER fibre Bragg grating measurement unit [9].

connection box that was installed and properly camouflaged at the top of the bridge main pier (figure 17).

\section{Numerical modelling, loading tests and results}

The primary objective for implementing a sensing network on the circular pedestrian steel bridge in Aveiro was to verify the real stress distribution in the suspension cables, beams and pier. Several measurements performed during loading tests allowed the calibration and validation of the numerical models adopted for the structural design and analysis (figure 18).

\subsection{Loading tests performed on the bridge}

Static and dynamic tests are frequently used before setting new bridges in service to verify the real structure behaviour and to compare it with that predicted by the numerical models. They allow a real representation of the structures response to static or dynamic loading and structural parameters data of the original undamaged structure, which can be used for future condition assessment.

Two series of static loading tests were carried out on the pedestrian bridge under study, the first in June 2006 and the second in November 2006, with the primary objective of controlling and evaluating the variation in time of the axial forces in the suspension cables. The measurements performed during the loading tests, registered by the sensing network installed, were used in the calibration of the numerical model developed for the design of the bridge. 


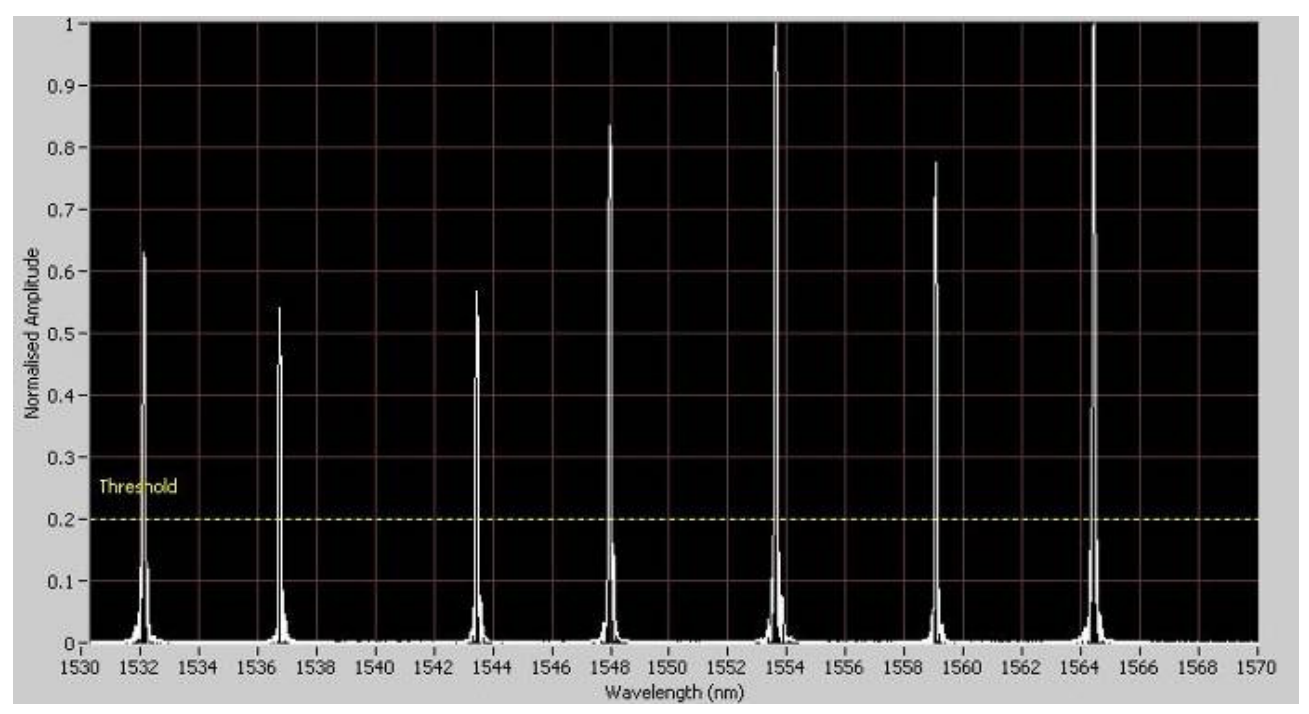

Figure 16. Reflected spectra from sensing branch 8 .

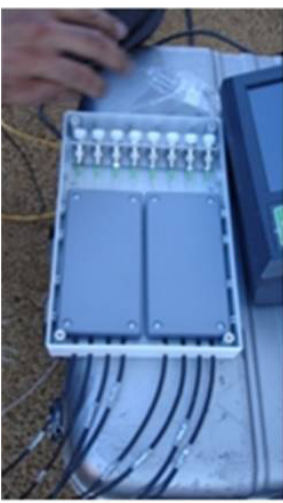

(a)

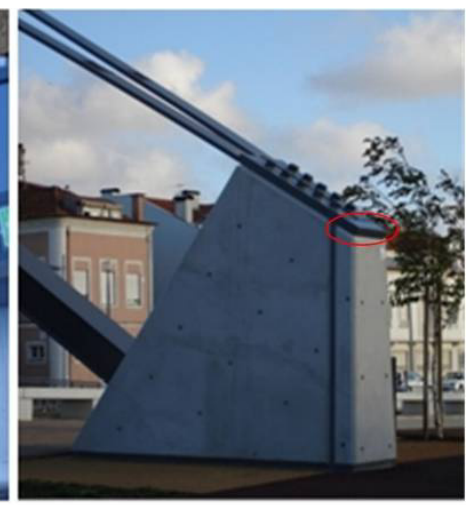

(b)
Figure 17. Connection box for the entire sensing network: (a) during assembling; (b) installed and camouflaged on the pier.

\subsection{Procedure}

In the loading tests performed, the load was accomplished by a group of people standing in specific locations on the bridge's deck, according to the four load configurations represented in figure 19.

Configurations $\mathrm{A}, \mathrm{B}$ and $\mathrm{C}$ correspond to concentrated loads at mid-span (three positions) and configuration D corresponds to a uniformly distributed load on the overall deck. In the first loading test (June 2006), the bridge was tested for the four load configurations and the group of people accomplished a total of $2293 \mathrm{~kg}$. In the second loading test (November 2006), only configurations A, B and C were considered and the total load was equal to $2378 \mathrm{~kg}$.

The duration of each loading was defined in order that the unit could scan all optical channels. Thirty samples per channel were programmed, with an acquisition rate of one sample per second. The switching time was approximately $1 \mathrm{~s}$, so the measurement time for each load configuration was slightly above 4 min (in practice, each load distribution was maintained for about $5 \mathrm{~min}$ ).

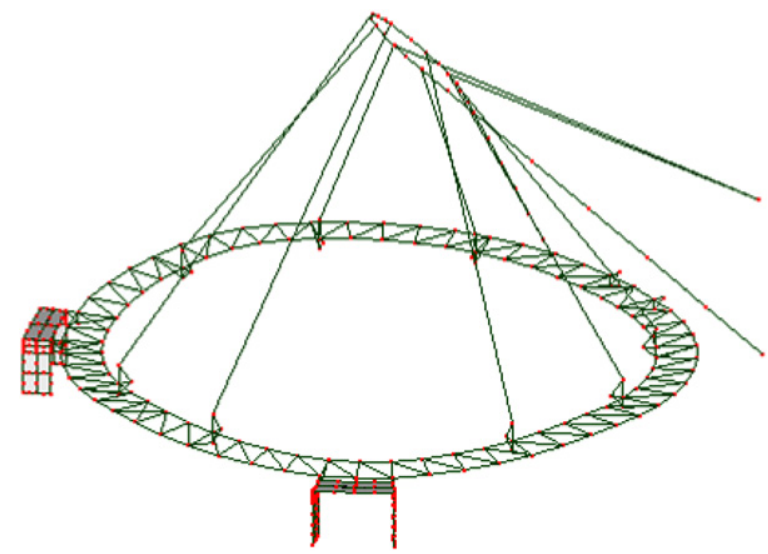

Figure 18. Numerical model for the simulation of the bridge structure.

The sensors were configured in order to obtain the results in terms of strain (in $\mu \varepsilon$ ) and temperature (in ${ }^{\circ} \mathrm{C}$ ).

\subsection{Loading test results}

The results from the loading tests were analysed in order to obtain an average value for each sensor in each loading configuration. Since the acquisition was done uninterruptedly, 30 values were considered for the average computation of each sensor after load stabilization. The same procedure was repeated for each channel during the programmed switching schedule.

An example of the measurement results is shown in figure 20, corresponding to the strain measured at the two sensors installed in the suspension cables 2 and 7 . Note that the first and also the last values presented in the charts correspond to the case of the bridge without additional loading (position ' $E$ '). This artifice was adopted to introduce a starting point in the graphic, which was not registered. 

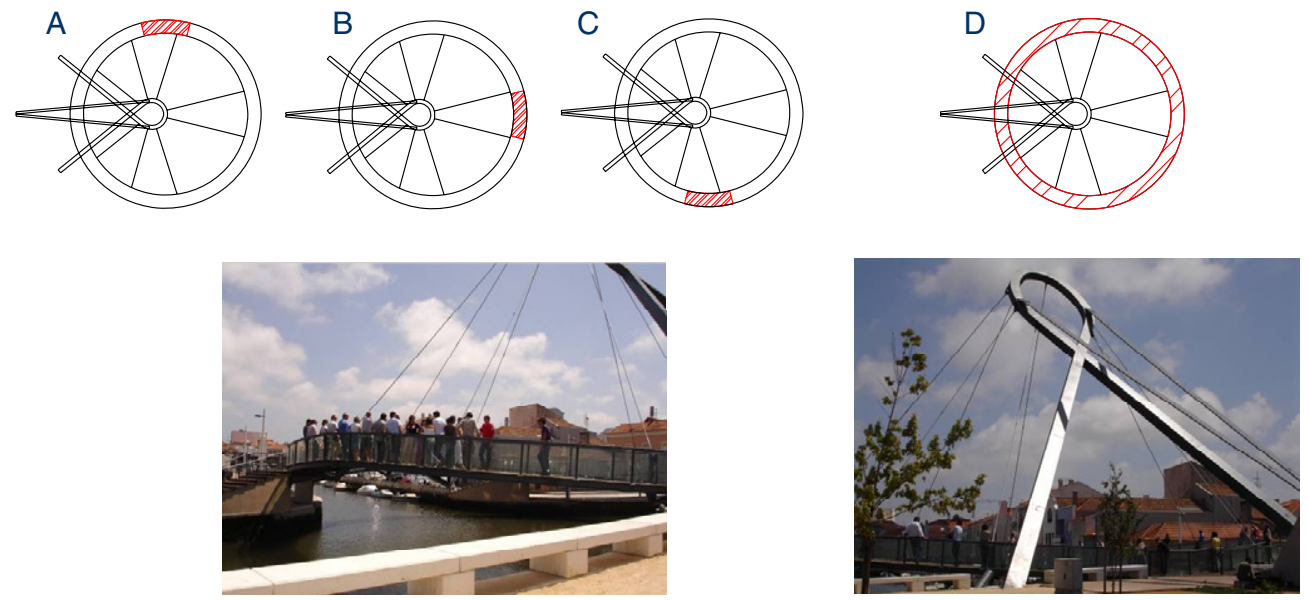

(a)

(b)

Figure 19. Load configurations applied to the bridge during the loading test: $(a)$ concentrated loads at mid-span (three positions); (b) uniformly distributed load on the deck.
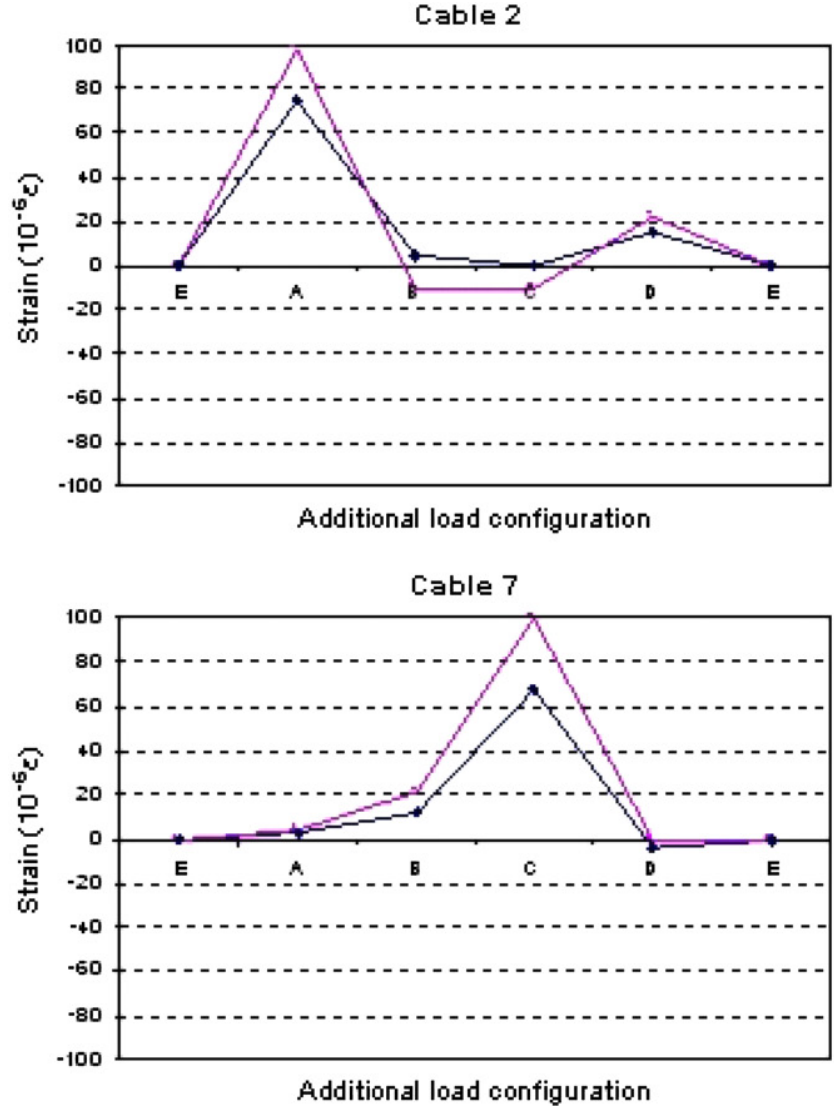

(a)

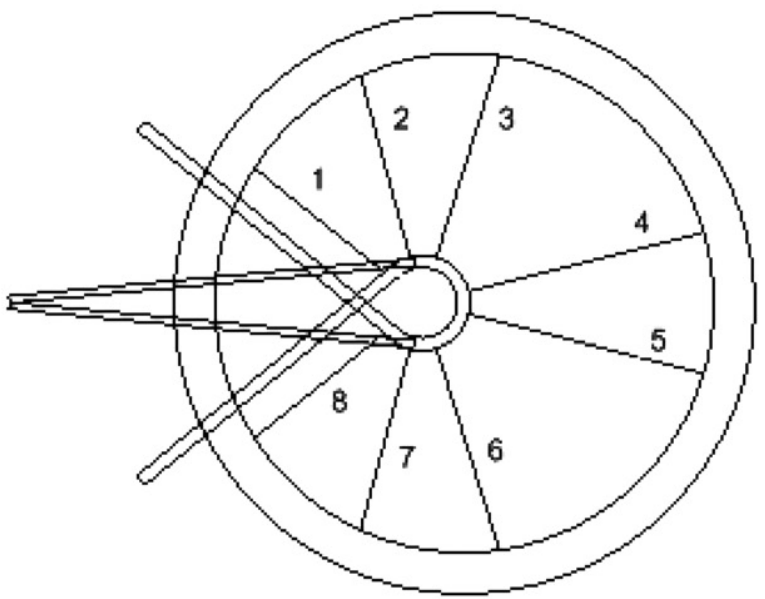

(b)

Figure 20. Test results: $(a)$ strain measured at the two sensors installed in the suspension cables 2 and 7 (note: E corresponds to no additional loading of the structure); $(b)$ schematics of the cables.

In table 1 are presented the results corresponding to the variation of axial forces in the cables, for the two loading tests and different load configurations.

\subsection{Numerical modelling}

The numerical model developed for the design and analysis of the bridge structure [10] (figure 20) was validated with the results of the loading tests performed (June and November 2006). The numerical model was developed in the program Robot Millennium [11]. Bar elements were used for the simulation of the steel elements (deck, suspension cables, suspension straps and post) and shell elements for the simulation of RC elements in the abutments. In the numerical model the axial force measured in the suspension cables was 
Table 1. Static loading test variation of axial forces in the suspension cables $(\mathrm{kN})$.

\begin{tabular}{|c|c|c|c|c|c|c|c|c|}
\hline \multirow{2}{*}{\multicolumn{2}{|c|}{$\begin{array}{l}\text { Structural } \\
\text { element }\end{array}$}} & \multicolumn{4}{|c|}{ Static test 1, $2293 \mathrm{~kg}$ (June 2006) } & \multicolumn{3}{|c|}{ Static test 2, $2378 \mathrm{~kg}$ (November 2006) } \\
\hline & & A & B & $\mathrm{C}$ & $\mathrm{D}$ & A & B & $\mathrm{C}$ \\
\hline \multirow[t]{8}{*}{ Cable } & 1 & -2.25 & -0.24 & 0.33 & 2.94 & -4.18 & -1.90 & -1.53 \\
\hline & 2 & 16.51 & -1.79 & -1.14 & 3.64 & & & \\
\hline & 3 & 13.74 & -1.59 & 1.46 & 1.32 & 11.31 & -4.72 & -2.76 \\
\hline & 4 & -2.64 & 12.95 & 1.81 & 0.79 & 2.28 & 13.43 & 0.15 \\
\hline & 5 & 1.55 & 9.30 & 0.66 & -0.36 & 1.38 & 8.67 & -4.80 \\
\hline & 6 & 1.20 & -2.12 & 9.09 & -0.07 & 0.94 & -1.75 & 0.15 \\
\hline & 7 & 0.10 & 2.42 & 17.74 & -0.02 & -1.54 & 0.32 & 15.12 \\
\hline & 8 & 0.33 & -0.16 & -0.81 & 0.57 & -0.39 & -1.55 & -4.33 \\
\hline
\end{tabular}

Table 2. Natural frequencies (numerical and experimental).

\begin{tabular}{ll}
\hline \multicolumn{2}{c}{ Frequencies $(\mathrm{Hz})$} \\
\hline Numerical & Experimental \\
\hline 3.13 & 3.17 \\
3.15 & 3.26 \\
3.98 & 3.80 \\
4.09 & 4.06 \\
4.79 & 4.59 \\
5.36 & - \\
\hline
\end{tabular}

considered, with the objective of representing precisely the forces on the structure measured during the tests, due to the self-weight of the bridge elements and to the pre-stress of each cable.

For the validation of the numerical model, dynamic tests were also performed and the natural frequencies and modal shapes of the bridge were identified [12]. Table 2 presents the natural frequencies measured and the frequencies obtained with the numerical model.

As can be observed in table 2, good agreement between the natural frequencies obtained experimentally and the natural frequencies calculated with the numerical model was obtained. It can be concluded that the numerical model represents properly the global dynamic behaviour of the bridge.

\subsection{Comparison between the experimental and the numerical results}

In the two series of loading tests performed on the bridge, the deformations on the suspension cables were measured with the installed fibre Bragg grating sensing network. Based on the location of the load applied and the corresponding value, the first static loading test (June 2006) was simulated on the numerical model. Table 3 presents the comparison, in terms of axial forces, of the measured values and the results obtained with the numerical model.

As can be observed in table 3 , for the first three load configurations (A, B and C), which correspond to the total load located between two suspension cables, the axial force measured experimentally is similar to the one obtained with the numerical model. The differences can be related to the load distribution during the experimental test, which was not perfectly uniform due to the nature of the load (group of people). In the other cables, not located in the vicinity of the deck region loaded, the variation of the axial force is lower, as expected. Concerning the last load configuration $(D)$, corresponding to a uniform load distribution along the overall bridge deck, the numerical model shows a symmetric variation of the forces.

\section{Conclusions and final comments}

New temperature and strain fibre Bragg grating sensors were developed for installation in a recently constructed circular pedestrian steel bridge over the São Roque and Botirões channels in Aveiro, Portugal. The sensors were developed for being directly welded to the steel structural elements following similar procedures to those of conventional weldable strain gages for the welding process is the most appropriate to ensure long-term reliability on the bonding of the sensor to metallic structures. In addition, proper installation procedures and protection means were established and implemented. The obtained results evidence linear response of the sensors for the required measuring range, and stability over load and temperature cycles. The deployment of the sensing network on the bridge also revealed to be practical albeit the particularly difficult installation conditions. The implemented fibre Bragg grating sensing network has been used for loading tests, and can also be used for real-time monitoring of the bridge structural health during service. Similar applications have been successful with this kind of sensors, namely railway bridges, opening bridges, tunnels and nautical structures.

The key objective of the two series of static loading tests performed on the bridge was to evaluate the eventual variations with time of the axial forces in its main structural elements. The results obtained in the two series of tests performed do not allow definitive conclusions about the axial forces variation. Therefore, additional tests are suggested to be performed, so accurate conclusions about the evolution of axial forces in cables can be made and a better understanding of the global behaviour of the bridge can be achieved. Although not definitely conclusive, the available results show coherent values in the maximum forces on the suspension cables more loaded, for each load configuration. Therefore, it can be considered that the bridge maintains similar behaviour between both loading tests (June and November 2006). It can be observed that the numerical model used in the structural 
Table 3. First static loading test of axial force on the suspension cables $(\mathrm{kN})$.

\begin{tabular}{|c|c|c|c|c|c|c|c|c|c|}
\hline \multirow{2}{*}{\multicolumn{2}{|c|}{$\begin{array}{l}\text { Structural } \\
\text { element }\end{array}$}} & \multicolumn{4}{|c|}{ Static test 1, $2293 \mathrm{~kg}$ (June 2006) } & \multicolumn{4}{|c|}{ Numerical model, $2293 \mathrm{~kg}$} \\
\hline & & A & B & $\mathrm{C}$ & D & A & B & $\mathrm{C}$ & $\mathrm{D}$ \\
\hline \multirow[t]{8}{*}{ Cable } & 1 & -2.25 & -0.24 & 0.33 & 2.94 & -2.81 & -0.37 & 0.47 & 2.26 \\
\hline & 2 & 16.51 & -1.79 & -1.14 & 3.64 & 12.00 & 0.81 & -0.46 & 2.99 \\
\hline & 3 & 13.74 & -1.59 & 1.46 & 1.32 & 15.63 & -2.20 & 1.12 & 1.40 \\
\hline & 4 & -2.64 & 12.95 & 1.81 & 0.79 & -2.83 & 12.53 & 0.81 & 1.53 \\
\hline & 5 & 1.55 & 9.30 & 0.66 & -0.36 & 0.80 & 12.51 & -2.83 & 1.52 \\
\hline & 6 & 1.20 & -2.12 & 9.09 & -0.07 & 1.10 & -2.18 & 15.69 & 1.41 \\
\hline & 7 & 0.10 & 2.42 & 17.74 & -0.02 & -0.46 & 0.82 & 12.03 & 3.00 \\
\hline & 8 & 0.33 & -0.16 & -0.81 & 0.57 & 0.47 & -0.37 & -2.82 & 2.25 \\
\hline
\end{tabular}

analysis reproduces accurately the global behaviour of the bridge.

\section{Acknowledgments}

The authors express their acknowledgment to Arch. Luís Viegas, Eng. Domingos Moreira and AVEIROPOLIS, Sociedade para o Desenvolvimento do Programa Polis em Aveiro, S.A., for the support given in the development of this work.

\section{References}

[1] Kincade K 2005 Fibre sensors lay groundwork for structural health monitoring Laser Focus World 42 63-7

[2] Ansari F (ed) 2005 Sensing Issues in Civil Structural Health Monitoring (Dordrecht: Springer)

[3] Crossley S D 2002 The commercialization of fibre optic sensors Handbook of Optical Fibre Sensing Technology ed J M López-Higuera (Chichester: Wiley)

[4] Krohn D 2006 Market opportunities and standards activities for optical fibre sensors 18th Int. Conf. on Optical Fibre Sensors (Cancun, 23-27 October 2006)

[5] Riviera E, Mufti A A and Thomson D J 2004 Civionics specifications for fibre optic sensors for structural health monitoring Proc. 2nd Int. Workshop on Structural Health Monitoring of Innovative Civil Engineering Structures ed A Mufti and F Ansari (Winnipeg: ISIS Canada Corporation)

[6] Udd E, Inaudi D, Culshaw B and Ecke W 2004 Fibre optic sensor opportunities and obstacles for aerospace and civil structure applications Panel Discussion in Smart Sensor Technol. and Measurement Syst._-SPIE Conf. 5384 (Smart Struct./NDE 2004, San Diego, 2004)

[7] Brönnimann R, Held M and Nellan P M 2006 Reliability, standardization and validation of optical fibre sensors $18 \mathrm{th}$ Int. Conf. on Optical Fibre Sensors (Cancun, 23-27 October 2006)

[8] Graver T, Inaudi D and Doornink J 2004 Growing market acceptance for fibre-optic solutions in civil structures Proc. of Fibre Optic Sensor Technology and Applications III ed M A Marcus, B Culshaw and J P Dakin pp 44-55 (SPIE vol 5589)

[9] Portable BraggMETER Data Sheet, available at www.fibersensing.com

[10] 2003 ROBOT MILLENIUM 17.5, Finite Elements Software, RoboBAT

[11] Viegas L and Moreira D 2005 Pedestrian bridge over the S Roque and Botirões channels-Drawings and Design Project

[12] Costa A, Varum H, Fernandes C, Rodrigues H and Miranda L 2007 Dynamic characterization and monitoring of a pedestrian bridge Technical Report Civil Engineering Department, University of Aveiro 